\title{
DIGITAL MODELLING AND ANALYSIS OF MASONRY VAULTS
}

\author{
G. Angjeliu ${ }^{1 *}$, G. Cardani $^{1}$, D. Coronelli ${ }^{1}$ \\ ${ }^{1}$ Dept. of Civil and Environmental Engineering, Politecnico di Milano, Piazza Leonardo da Vinci, Milan, Italy - (grigor.angjeliu, \\ giuliana.cardani, dario.coronelli)@polimi.it
}

KEY WORDS: Masonry, Cross-vault, Point-cloud, Building Information Modelling, Finite Element Analysis, Structural assessment.

\begin{abstract}
:
The focus of this paper is to discuss the peculiarities of the digital modelling of masonry cross vaults. The proposed methodological approach for a multidisciplinary study of masonry vaults will be focused on: geometrical survey, crack pattern, geometrical modelling, and safety assessment based on structural analysis.

Automatic reconstruction procedures recently proposed in the literature for ribbed masonry vaults, are used to overcome timeconsuming modelling tasks. The created digital models take into consideration the different aspects of the three-dimensional geometry, the internal divisions with variations of material properties in different parts, and a suitable discretization for finite element analysis. Moreover, the same model can be used in BIM (Building Information Modelling), judged as a suitable environment in which to combine different aspects of the restoration works such as: documentation, intervention design, and the data system in an unique model. The same model is then used to perform finite element analysis. Each of these aspects is clarified with examples of different vaults typology coming from case studies as that of the church of St. Bassiano in Pizzighettone (Cremona) or the notable Milan Cathedral.
\end{abstract}

\section{INTRODUCTION}

Nowadays, digital models are a common requirement in restoration projects, which in order to be an integral part in the design of a conservation project need to include many aspects of the object under study: the actual three-dimensional configuration, the design of technical interventions, the design of the monitoring system, the structural assessment, the planning of the maintenance, etc.

The technical difficulties in creating digital models are particularly elevated in vaulted masonry buildings due to the need to model complex geometry, its construction technique, materials, and different reconstructions over time. Moreover, different typologies are found in practice, i.e. quadripartite, sexpartite, and with very different shapes in plan: triangular, trapezoidal, square, rectangular depending on the epochs in which they were constructed and their function in the given building (Acland, 1972; Fitchen, 1981). Digital models of masonry vaults must include the main members: tas-de-charge, arch, rib, web, crown and rubble-fill.

Point cloud data (derived from photogrammetric or laser scanning) provide important information on the metrics required for geometric modelling, but also for the documentation of crack pattern. Nevertheless, the point cloud data cannot be used in a straightforward manner to obtain the masonry vault digital model, as the thickening of the point cloud surface in the normal direction (usually the intrados) does not result in the real geometry, as self-intersection of solids appearing in corner regions near the ribs and arches.

Accurate models of the masonry vault should include these known details with solid elements without tending to reduce a complex three-dimensional system with two dimensional elements (e.g. as the common shell modelling approach). Such models can be then suitable for multipurpose use: documentation, design of technical interventions, or structural assessment of masonry cross vaults.

Digital models must be suitable for use in different software, deepening the interoperability issue, in order to meet the needs of different users working in the AEC Industry e.g. CAD, BIM or FEM (Del Giudice and Osello, 2013). In particular BIM (Building Information Modelling) is judged as a suitable platform to combine different aspects of the restoration works such as: documentation, intervention design, and the data control system in a unique model (Bassier et al., 2018; Brumana et al., 2013; Cardani and Angjeliu, 2016; Milani et al., 2018; Volk et al., 2014).

In this paper a particular focus will be directed on the integrated use of geometric survey, geometric modelling for documentation and structural analysis of masonry cross vaults. The procedure is illustrated by taking as case study the vaults in the nave of the church of St. Bassiano in Pizzighettone (Cremona) and in Milan cathedral. Geometric data required for modelling are extracted from photogrammetric point cloud survey of each case study. The digital models of the masonry vaults are created using an automatic reconstruction procedure proposed recently in the literature for ribbed masonry vaults (Angjeliu et al., 2019a). It successfully overcomes timeconsuming modelling tasks as well as interoperability issue between geometric modelling (CAD or BIM) and structural analysis software. An important aspect discussed is the combination of in situ observations and modelling. Finally, the aspect of structural assessment and interpretation of damage observations is discussed about the church of St. Bassiano, where a diffused system of cracks is visible in the vaulting system. 


\section{ISSUES ON DIGITAL SURVEY}

Metric survey of cross vaults is difficult to carry out with simple tools, hence more sophisticated ones such as photogrammetry or laser scanning are judged as more appropriate.

Two case studies taken into consideration throughout this paper analyse the vaults in the nave of Milan Cathedral and the church of St. Bassiano (Figure 1a, b). They are of the same period and typology, but with different proportions. In Milan Cathedral the nave vaults are quadripartite with dimensions 9.6 m x 19.2 m (Coronelli et al., 2015), while in the church of St. Bassiano we have the quadripartite vaults of smaller dimensions, $4.4 \mathrm{~m}$ x $7.1 \mathrm{~m}$ (Cardani and Massetti, 2017).

The geometric survey was carried out with digital photogrammetry. A part of the point cloud considering only the vaults in the nave is shown in Figure 2. The point cloud should be detailed enough to capture geometric details of the surveyed ribbed vault, that are relevant for a structural study. The present point cloud describes the visible surface of the vault (intrados) and contain around $5000-10000$ point per vault. In most cases, measurements include only the intrados, due to the difficulty to physically access the extrados. In other cases where accessible there is extra work to be done (as well as extra costs) in order to connect the two sets of measurements.

Point cloud data (derived from photogrammetric, laser scanning or lidar sensors) provide important information on the metrics required for geometric modelling. Moreover, the fact that the point cloud is denser in regions where geometric features (e.g. arch, rib) are to be extracted, is an advantage and increases the accuracy of computations.

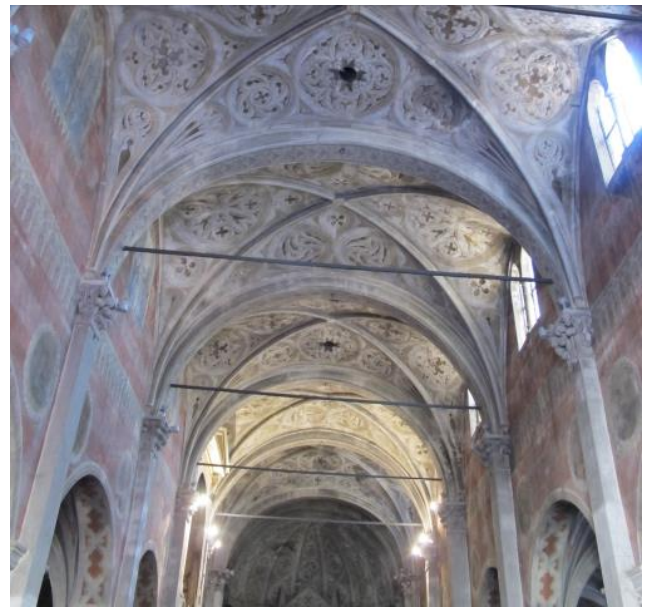

a)

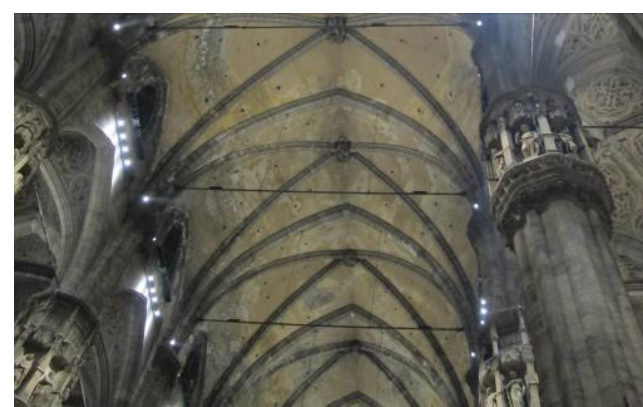

b)

Figure 1. View of masonry vaults in the central nave: a) Church of St. Bassiano, b) Milan Cathedral
The identification of geometric shapes, is carried out by fitting the equation of a circular or elliptic arc in a subspace of points describing the object of interest (e.g. arch, rib, web, etc.) (Angjeliu et al., 2019b). From a mathematical point of view the number of the points in the selected subset is usually more than 3 , hence we expect an overdetermined system of linear equations:

$$
\mathrm{Cu}=\mathbf{r}
$$

where:

$\mathrm{C}$ - coefficient matrix

$\mathbf{u}-$ vector of unknowns

$\mathbf{r}-$ residual

The system is solved for $\mathrm{u}$ to minimize $\|\mathrm{r}\|$ :

$$
\|\mathbf{C u}\|=\min , \text { subject to }\|\mathbf{u}\|=1
$$

The system can be solved iteratively with the Gauss-Newton method. It is now possible to identify the geometric shape to be used for modelling the arch. An example considering the identification of the geometric shape (circular or elliptic), radii, centre point by using the least square minimisation procedure is shown in Figure 4.

In a more general case, e.g. a multi-centred arch, the application of piecewise approximation is required. Although slightly more elaborate, it remains in principle the same, by applying the least squares problem.

Within a structural context, more information is necessary regarding the internal construction of masonry vaults, which unfortunately cannot be provided by point cloud data.

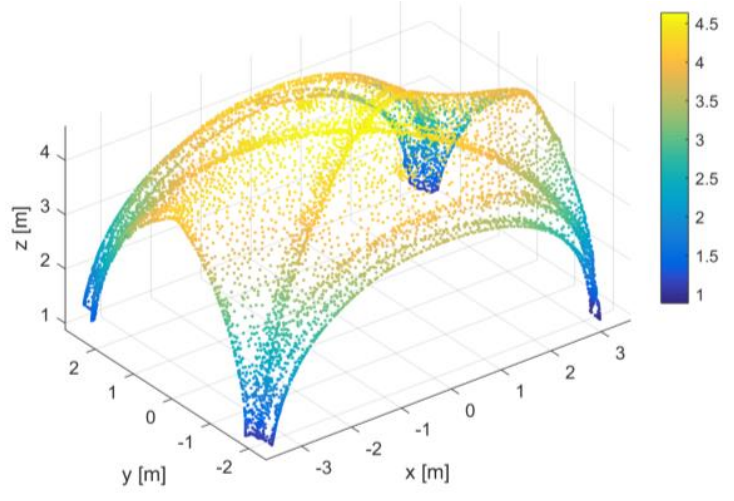

Figure 2. St. Bassiano Church: Point cloud of vault in the nave

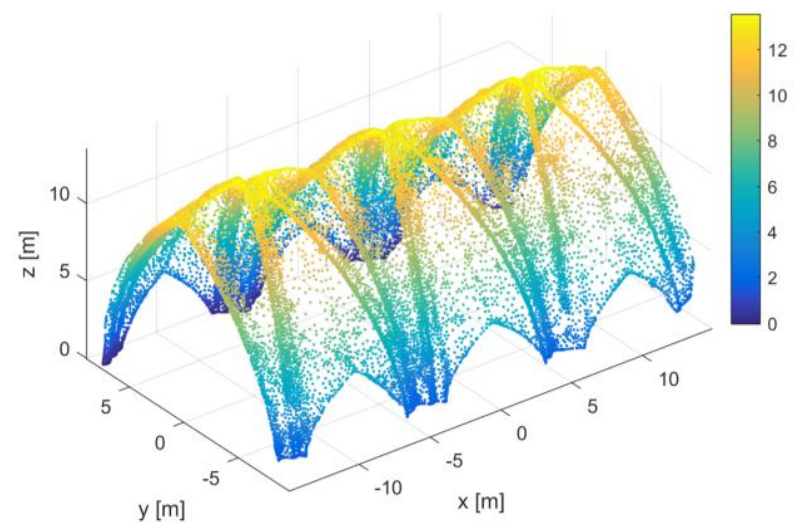

Figure 3. Milan Cathedral: Point cloud of the vaults in the nave 


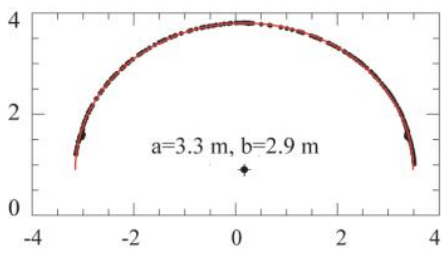

a)

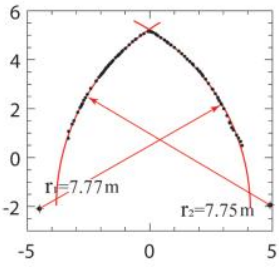

b)
Figure 4. Shape identification in point-cloud by least square minimization procedures (Angjeliu et al., 2019a): a) arch in St.

Bassiano church, b) arch in Milan cathedral

Therefore, the correlation of the digital survey (described up to this point) and direct in-situ observations (constructive details, non-destructive investigations) within the same model becomes important. In other cases, historic data (literature and archival data, technical reports) can be used to describe the construction of a known vault typology.

The detail of the in-situ inspection in the vaults of the nave of the church of St. Bassiano are shown in Figure 5. The construction details of the vaults are visible only from the extrados (in Figure 5a, b) or after the removal of plaster (Figure $5 \mathrm{c})$. The ribs are made of brick and covered with a thick layer of plaster (Figure 5c). The arch in the arcade is observed to be made of bricks, oriented radially, while the web is made of masonry, with the brick courses oriented parallel to the main direction of the vault arches (Figure 5a, b).

In difference to that in Milan Cathedral, the pointed arches are made of stone voussoirs and the cross-section height is $0.57 \mathrm{~m}$, while for the rib the cross-section height is $0.52 \mathrm{~m}$. The web is made of brick masonry, $0.38 \mathrm{~m}$ thick. Hence the role of ribs is imported in the structural response of the system as it will be shown later on in this article.
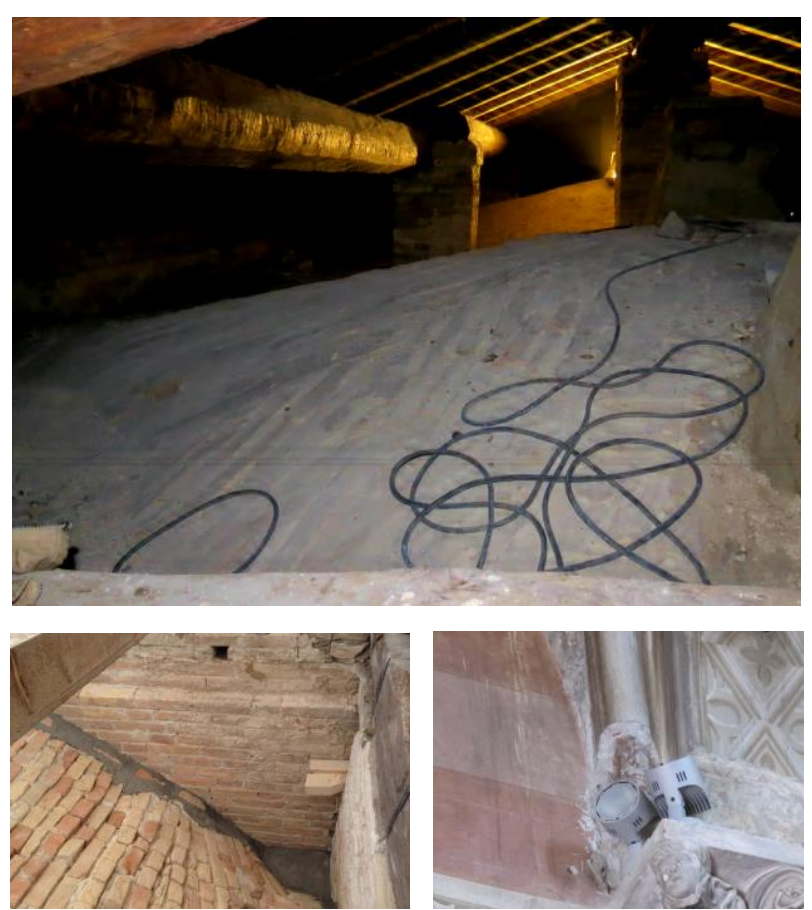

Figure 5. Construction details in masonry vaults in the church of St. Bassiano: a, b) masonry texture in the web, c) detail of the rib after a local inspection

\section{DIGITAL MODELLING}

As argued previously in the introduction, the point cloud data cannot be use in a straightforward manner to obtain the masonry vault geometric model, in order to be used as a correct representation of the original element (which is made of different parts) also for structural analysis applications. Moreover, there is the possibility to obtain detailed threedimensional models, with the accuracy tailored to the required objectives of the analysis, thanks to the high level of digital technology available. Within this context, modelling the cross vaults will be investigated in:

\section{- BIM environment \\ - FEM environment}

The Autodesk Revit software is adopted to investigate the BIM environment, while Simulia Abaqus software is chosen to set up the structural modelling with the finite element method. Compared to a traditional CAD model, BIM models have more similar geometry modelling requirements with FEM models e.g. intersection and overlapping of parts (components) are not allowed. Therefore, it creates the possibility to use the same geometric model for documentation and structural analysis.

Automatic reconstruction procedures recently proposed in the literature for ribbed masonry vaults based on parametric modelling, are used to model the two vaults object of this study (Angjeliu et al., 2019a). The generated models for the two case studies includes all the typical members of a ribbed masonry vault created with solid elements: arch, rib, web, rubble-fill, and nodal zones (tas-de-charge) (Angjeliu et al., 2019a). It can be used to create cross vaults models in BIM and FEM.

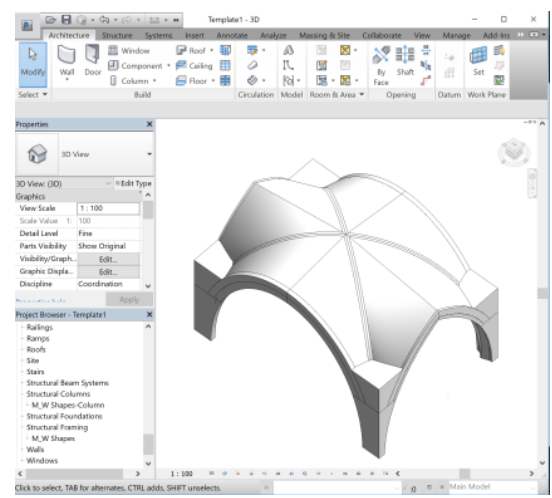

a)

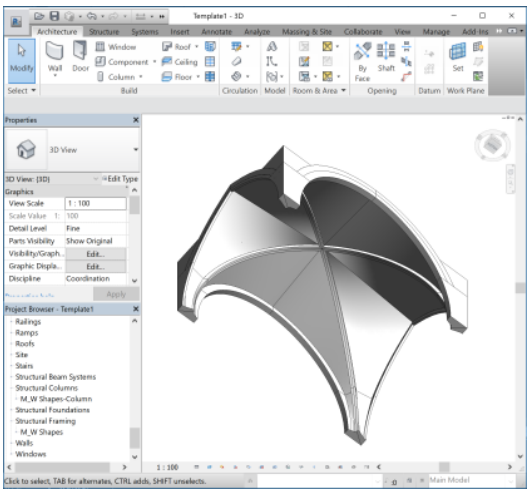

b)

Figure 6. Masonry vault in the church of St. Bassiano: a) extrados, b) intrados 


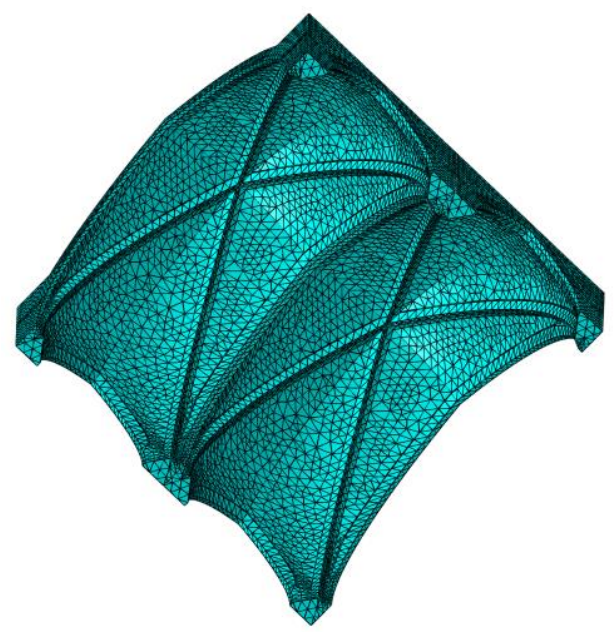

Figure 7. Vault in Milan cathedral. Mesh with tetrahedral elements for numerical simulations

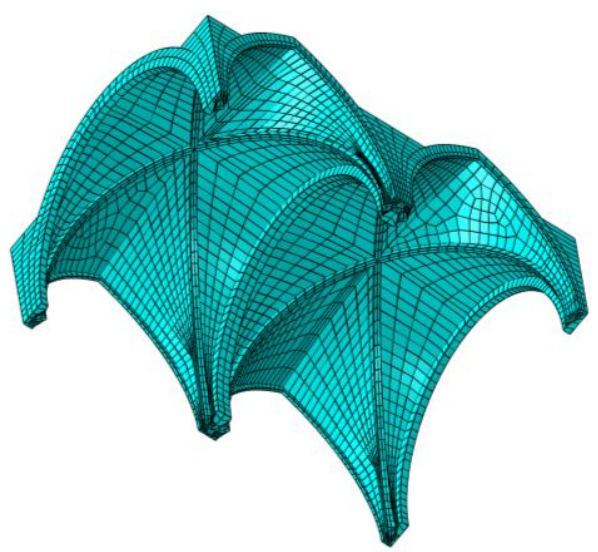

Figure 8. Vaults in the nave of the church of St. Bassiano: Mesh with hexahedral elements for numerical simulations

In Revit the created model is imported as a Revit Family Component, through an ACIS file (SAT file extension). The created family can be then loaded within a specific Revit Template (Architecture, Construction, Structural, etc.). An example of creating a family component of the masonry vault in the church of St. Bassiano and using it within a BIM construction template is shown in Figure 6. The same model can then also be used also within a structural analysis software. Figure 7 shows the internal parts of the digital model of the ribbed vaults in the nave of Milan Cathedral imported in Abaqus software and meshed with tetrahedral elements. The model includes the stone skeleton which comprises the arches, ribs, masonry web which typically lies over the arch and rib skeleton and the rubble-infill. Figure 8 shows the second model (cross vault in the nave of the church of St. Bassiano) after the discretization with hexahedral finite elements in Abaqus.

Finally, the created models through the adopted procedure based on parametric modelling take into consideration the complex three-dimensional geometry with the internal divisions between structural parts, and an optimal discretization for finite element structural simulations with hexahedral or tetrahedral elements.

\section{OBSERVED DAMAGE AND STRUCTURAL ASSESMENT OF MASONRY VAUTLS}

Typical damage observed in the masonry cross-vaults usually arouses concerns about the safety of the structural system. Interpretation based only on personal experience must be avoided, when taking into consideration the available level of technology and data widely available and due to the very different masonry vaults typologies present in historical constructions.

In order to develop more effective and minimal repair measures, Barthel (1993) discussed on the need to understand the crack pattern observed in historical buildings by proposing a comparison with numerical simulation. Further understanding of the structural behaviour could be developed through experimental investigating. Torres et al. (2019) concluded on the important cyclic vertical support settlements on the structural response of cross vaults.

The intensity of the observed damage in the two masonry vaults here analysed are different. In the vault of the central nave of Milan Cathedral no serious damage is observed, with exception of particular areas which are characterised by specific structural configuration (e.g. Tiburio or apse) and are not the object of the present study. The remaining part of visible damage is related to humidity rather than structural actions. In difference to that, in the vault of the central nave in the church of St. Bassiano, a diffused crack pattern is observed (Figure 9), with a nearly continuous crack in the longitudinal direction. It starts close to the façade and continues in the nave until the apse (Cardani and Massetti, 2017). Here, other cracks documented in the foundations (e.g. close to the apse), enforce the idea that soil settlements are an important possible cause. Therefore confirming the differential settlements hypothesis (Angjeliu, 2018). Another reason for the present crack pattern is found in historical information, stating change of the load in the piers and cause of supplementary settlements due to the addition of the masonry vaults centuries after the church construction, as well as other smaller structures (Cardani and Massetti, 2017)

Structural assessment by simplified methods may fail to give an interpretation on the observed damage, due to an excessive level of the simplification of the reality. On the other hand, complex structural models, have the benefit of being able to predict most of the observed damage, hence supply an interpretation on the damage observation.

In the following two detailed finite element structural models of the two vaults are studied due to self-weight. Furthermore, the case of St. Bassiano is studied also under different possible support settlements. In both models, the iron tie rods are not inserted explicitly with the aim of studying the structure only under clear self-weigh and settlement effects. Further details on the behaviour of structures with iron tie rods can be found on (Angjeliu et al., 2018; Bellanova and Felicetti, 2019).

In the simulations, the masonry web, the stone arch and the

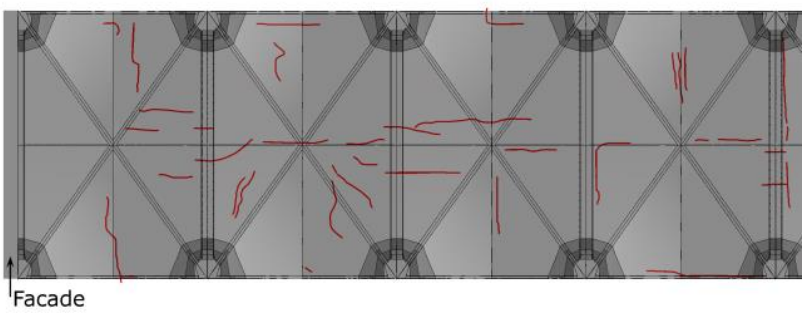

Figure 9. Documentation of the crack pattern in the nave of the church of St. Bassiano within BIM environment 
rubble infill are modelled with a non-linear plastic damage constitutive model according to the description of (Lee and Fenves, 1998; Lubliner et al., 1989).

The stone masonry (arch and rib in Milan Cathedral) is modelled with an elastic modulus, $\mathrm{E}=8000 \mathrm{Mpa}$, compressive strength, $\mathrm{fc}=7 \mathrm{MPa}$ and fracture energy in compression, $\mathrm{G}_{\mathrm{fc}}$ $=1.5 \mathrm{Nmm} / \mathrm{mm}^{2}$, while the tensile branch with a strength $\mathrm{f}_{\mathrm{t}}=$ $0.35 \mathrm{MPa}$ and a fracture energy $\mathrm{Gft}=0.02 \mathrm{Nmm} / \mathrm{mm}^{2}$. The brick masonry (web of both case studies and arch and rib in St. Bassiano church) is modelled with an elastic modulus, $\mathrm{E}=2000$ $\mathrm{MPa}$, compressive strength, $\mathrm{fc}=5 \mathrm{MPa}$ and fracture energy in compression, $\mathrm{G}_{\mathrm{fc}}=1.2 \mathrm{Nmm} / \mathrm{mm}^{2}$, while the tensile branch with a strength $\mathrm{f}_{\mathrm{t}}=0.25 \mathrm{MPa}$ and a fracture energy $\mathrm{Gft}=0.012$ $\mathrm{Nmm} / \mathrm{mm}^{2}$. The rubble infill is modelled with a modulus of elasticity, $\mathrm{E}=800 \mathrm{MPa}$, compressive strength, $\mathrm{fc}=2 \mathrm{MPa}$ and fracture energy in compression, $\mathrm{G}_{\mathrm{fc}}=0.5 \mathrm{Nmm} / \mathrm{mm}^{2}$, while the tensile branch with a strength $\mathrm{f}_{\mathrm{t}}=0.15 \mathrm{MPa}$ and a fracture energy $\mathrm{G}_{\mathrm{ft}}=0.01 \mathrm{Nmm} / \mathrm{mm}^{2}$ (basically a material with scarce properties). The volumetric weights for each material are 22 $\mathrm{kN} / \mathrm{m}^{3}, 18 \mathrm{kN} / \mathrm{m}^{3}$ and $16 \mathrm{kN} / \mathrm{m}^{3}$, respectively.

The proposed methodology is shown to be efficient in order to study the load flow in masonry cross vaults. In particular, the results demonstrate no development of damage under selfweight, hence leaves it to other causes.

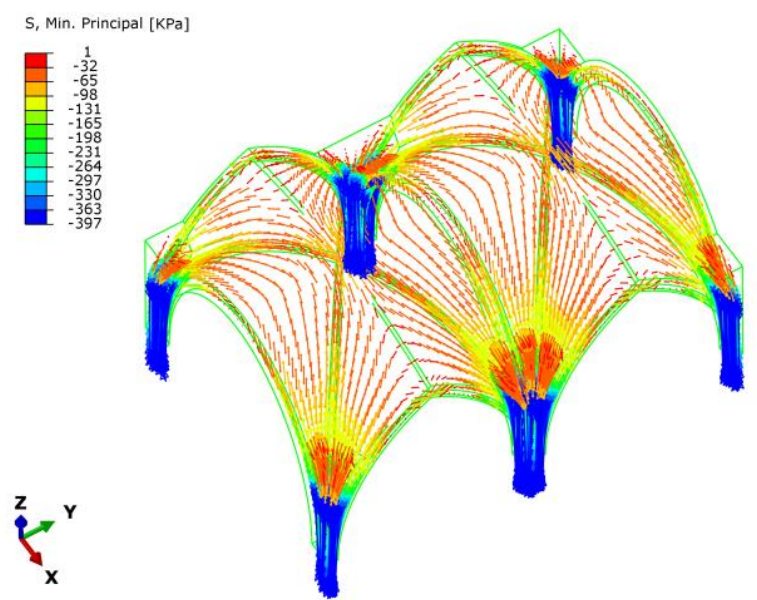

Figure 10. St. Bassiano Church: Vector plot of the compressive principal stresses due to self-weight (without settlement)

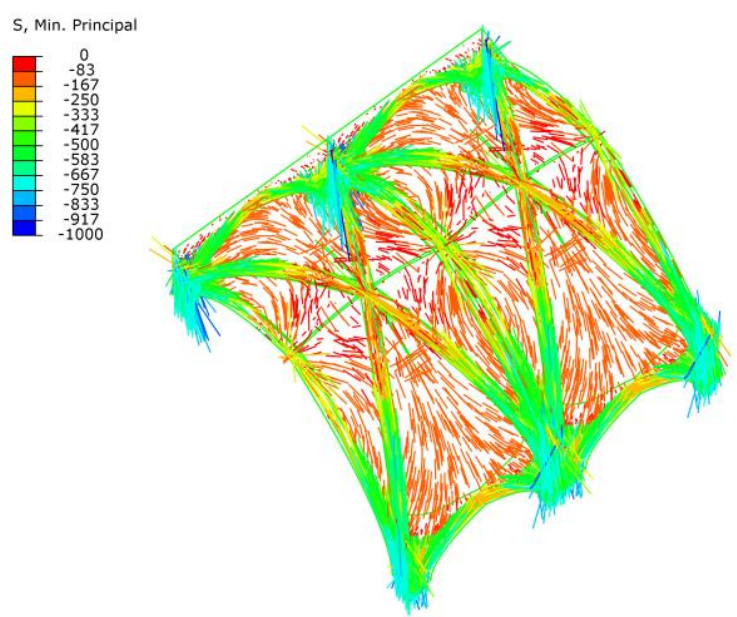

Figure 11. Milan Cathedral: Vector plot of the compressive principal stresses due to self-weight (without settlement)
In the case of the vault of Milan Cathedral the computed horizontal thrust is $\mathrm{H}=268 \mathrm{kN}$, while the vertical force $\mathrm{V}=1726$ $\mathrm{kN}$ for each support. In the case of the vault in the church of St. Bassiano the horizontal thrust is $\mathrm{H}=52 \mathrm{kN}$, while the vertical reaction $\mathrm{V}=132 \mathrm{kN}$. In the latter, similar results were calculated also using the limit analysis solution in the masonry vaults in (Angjeliu, 2018).

The investigation of the load flow through the principal compressive stresses shows a very regular flow of forces pointing at tas-de-charge in the case of St. Bassiano (Figure 10). Moreover, in the rib area there is not a concertation of stresses as usually found in other ribbed masonry vaults (Angjeliu et al., 2019a). While diversely, in Milan Cathedral vault, the load flow shows a mixed tendency to be directed in part to the tas-decharge and in part to the ribs and arches (Figure 11). The difference of the load flow in the two cases is related to the considerable difference of the rib section height (e.g. almost 5 times).

Other aspects to be investigated are the settlement effects in the observed crack pattern. The case of St. Bassiano is investigated under different support settlements which in order to understand the actual causes of the observed crack pattern:

a) Vertical settlement over one support

b) Vertical settlement applied in two supports at different stages of time.

c) Vertical settlement of all the supports on one side

d) Horizontal settlement of all the support on one side

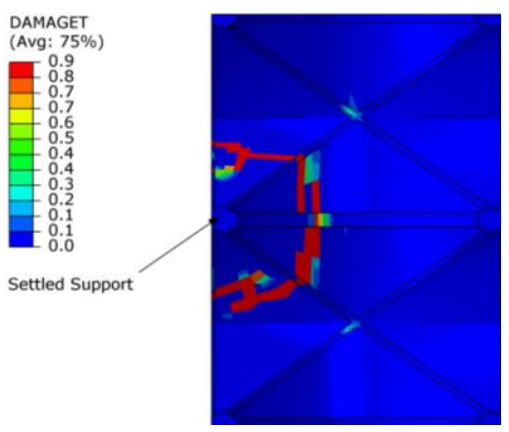

a)

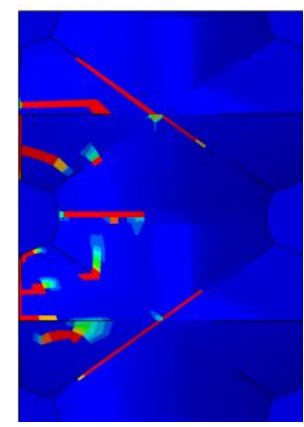

b)
Figure 12. Damage simulation due to single vertical support settlement: a) intrados view, b) extrados view

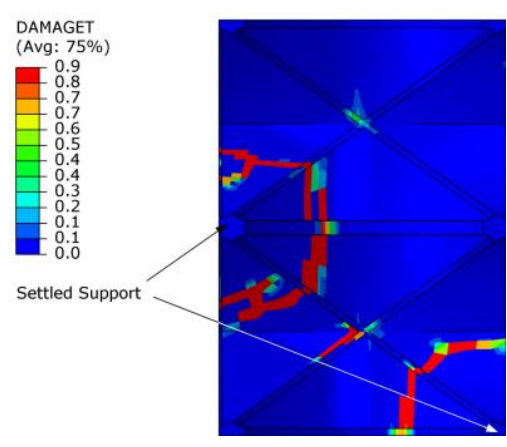

a)

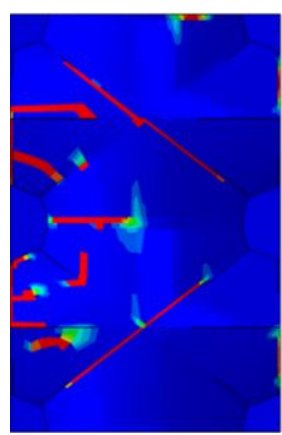

b)
Figure 13. Damage simulation due to combination of asymmetric vertical support settlements applied in two stages:

a) intrados view, b) extrados view 
In all the analysis the considered entity of settlement is $1 \mathrm{~cm}$, in order to investigate its effects on the produced crack patter in the vaulting system of St. Bassiano church. The analyses result first of all provide an interpretation of the causes of damage (Figure 12 - Figure 15). The results show that the documented crack pattern (Figure 9), is not a result of a single support settlement, but a combination of different factors.

An interesting fact that is noted is that the crack pattern should be much diffused also in the extrados, although unfortunately, no documentation is available in the present. The cracks simulated in the extrados find confirmation also in experimental studies of masonry cross vaults (Torres et al., 2019).

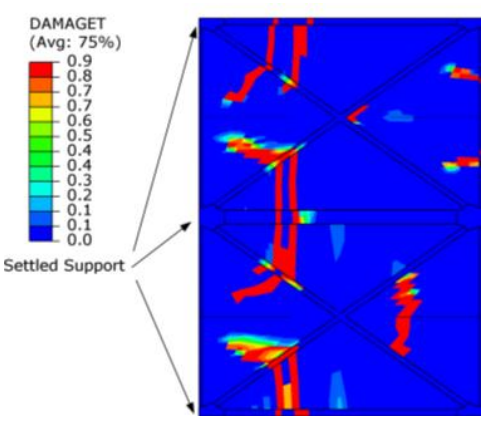

a)

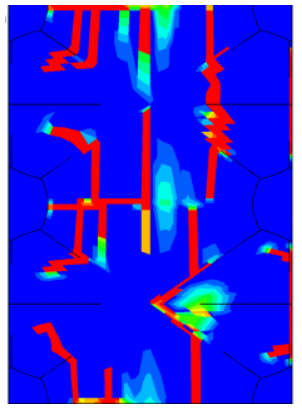

b)
Figure 14. Damage simulation due to vertical support settlement: a) intrados view, b) extrados view

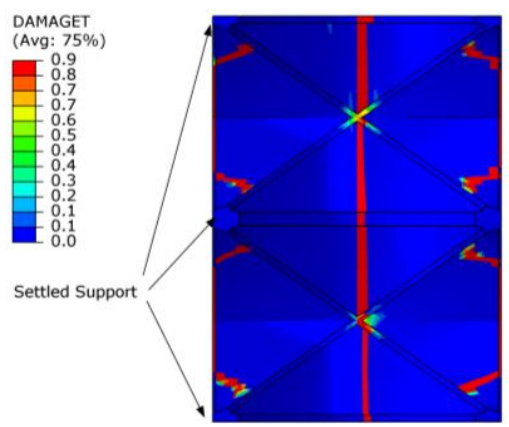

a)

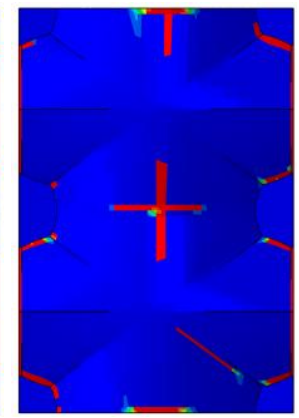

b)
Figure 15. Damage simulation due to horizontal support settlement: a) intrados view, b) extrados view

\section{CONCLUSIONS}

The described methodological approach in this paper includes survey, documentation, digital modelling and structural assessment. It was shown to be necessary to consider different ingredients in the digital modelling process of masonry vaults such as: point cloud measurements, in-situ investigations or the need to model the geometry with solid elements.

The accurate geometric survey of the masonry cross vaults is important in understanding and modelling its structural configuration. The in-situ observation and diagnostic investigations help to better understand the constructive details and possible causes of the observed damage.

The masonry vaults models created here through parametric modelling, were successfully used for geometric documentation in BIM as well as for finite element structural analysis. The numerical simulations with solid elements developed here, approximating as much as possible the reality, help to understand the structural behaviour of complex masonry vaults, under self-weight conditions as well as under differential soil settlements.

The two analysed case studies clearly show how the technology of construction is reflected in the structural response: ribbed masonry vaults with stiff stone ribs in Milan cathedral and flexible brick ribs in the case of St. Bassiano church. The simulations clearly mark the advantage of developing complex models with solid elements. Compared to shell approach (diffused in the literature), models with solid elements permit to study zones of intersection between different structural elements as: rib, arch, web, wall, infill. Furthermore, it is possible to investigate the stress transfer between different elements as well as the damage evolving within the element thickness. This modelling technique allows also to model and study the effectiveness of strengthening interventions, which in most of the cases are applied in the extrados (in order to be invisible or not to damage possible frescoes in the intrados).

Taking advantage also of the automatic structural modelling procedure and the created detailed models, future developments could include the investigation of the structural response of different typologies of masonry vaults combining survey, damage observation and numerical modelling.

\section{ACKNOWLEDGEMENTS (OPTIONAL)}

The authors are grateful to the Veneranda Fabbrica del Duomo di Milano, for making it possible to work in the Cathedral of Milan. We also thank Don. Enrico Maggi, Don. Andrea Lamperti and Ing. Gian Ermes Massetti for access, and support with data during the study of the Church of St. Bassiano in Pizzighettone (Cremona).

\section{REFERENCES}

Acland, J.H., 1972. Medieval structure: the gothic vault. University of Toronto Press.

Angjeliu, G., 2018. Integrated structural modelling and experimental observations in historic masonry constructions, $\mathrm{PhD}$ Thesis, Department of Civil and Environmental Engineering. Politecnico di Milano, Milan (IT), Politecnico di Milano, p. 312.

Angjeliu, G., Cardani, G., Coronelli, D., 2019a. A parametric model for ribbed masonry vaults. Automation in Construction.

Angjeliu, G., Coronelli, D., Cardani, G., 2018. Structural modelling of complex historic masonry buildings, 10th International Masonry Conference, Milan, Italy.

Angjeliu, G., Coronelli, D., Cardani, G., 2019b. Challenges in Modelling Complex Geometry in Historical Buildings for Numerical Simulations, in: Cocchiarella, L. (Ed.), The 18th International Conference on Geometry and Graphics. Springer, Milan, Italy, pp. 1218-1230.

Barthel, R., 1993. Crack Formation in Masonry Cross Vaults. IABSE REPORTS, 393-393.

Bassier, M., Hardy, G., Bejarano-Urrego, L., Drougkas, A., Verstrynge, E., Van Balen, K., Vergauwen, M., 2018. Semi- 
automated creation of accurate FEM meshes of heritage masonry walls from point cloud data, International Conference on Structural Analysis of Historical Constructions edition:11, Peru.

Bellanova, M., Felicetti, R., 2019. A Multidisciplinary Strategy for the Inspection of Historical Metallic Tie-Rods: The Milan Cathedral Case Study. International Journal of Architectural Heritage, 1-19.

Brumana, R., Oreni, D., Van Hecke, L., Barazzetti, L., Previtali, M., Roncoroni, F., Valente, R., 2013. Combined Geometric and Thermal Analysis from Uav Platforms for Archaeological Heritage Documentation. ISPRS Annals of Photogrammetry, Remote Sensing and Spatial Information Sciences II-5/W1, 49-54.

Cardani, G., Angjeliu, G., 2016. Challenges from building information modeling to finite element analysis of existing buildings, 10th International Conference on Structural Analysis of Historical Constructions. CRC Press, Leuven, Belgium, p. 120 .

Cardani, G., Massetti, G.E., 2017. When the strengthening of historic masonry buildings should be carried out in different phases: the structural reinforcement and monitoring of the Lombard-Romanesque church of Saint Bassiano, in Pizzighettone (CR), Italy, PROHITEC'17-3rd International Conference on Protection of Historical Constructions. IST Press, pp. 1-12.

Coronelli, D., Caggioni, B., Zanella, F., 2015. The Cathedral of Milan: the structural history of the load-bearing system. International Journal of Architectural Heritage.

Del Giudice, M., Osello, A., 2013. BIM for cultural heritage. International Archives of the Photogrammetry, Remote Sensing and Spatial Information Sciences 5, 225-229.

Fitchen, J., 1981. The construction of Gothic cathedrals: a study of medieval vault erection. University of Chicago Press.

Lee, J.H., Fenves, G.L., 1998. Plastic-damage model for cyclic loading of concrete structures. J Eng Mech-Asce 124, 892-900.

Lubliner, J., Oliver, J., Oller, S., Onate, E., 1989. A PlasticDamage Model for Concrete. International Journal of Solids and Structures 25, 299-326.

Milani, G., Shehu, R., Valente, M., 2018. Simple limit analysis approach for the optimal strengthening of existing masonry towers, AIP Conference Proceedings. AIP Publishing, p. 450007.

Torres, B., Bertolesi, E., Calderón, P.A., Moragues, J.J., Adam, J.M., 2019. A full-scale timbrel cross vault subjected to vertical cyclical displacements in one of its supports. Engineering Structures 183, 791-804.

Volk, R., Stengel, J., Schultmann, F., 2014. Building Information Modeling (BIM) for existing buildings Literature review and future needs. Automation in Construction $38,109-127$. 